\title{
La evasión de Mnemosine, museologías para la construcción política
}

\author{
The evasion of Mnemosyne, museology for political construction
}

Sigal Meirovich

Universidad SEK

Sigal.meirovich@gmail.com

\section{Resumen:}

La incorporación de Pinochet en la última exhibición temporal del Museo Histórico Nacional de Chile "Hijos de la Libertad. 200 años de independencia" posibilitó una nueva irrupción de memoria en el presente. El debate público que suscita fue caracterizado por los medios de prensa como una batalla entre museos emblemáticos debido a que el Museo de la Memoria y los Derechos Humanos, junto a otros actores, acusan al primero de transgredir el marco ético de los Derechos Humanos y de transgredirse a sí mismo en ello. El último triunfa en hegemonizar el campo del pasado reciente constituyendo su estructura lógica como modo legítimo de representación. En el presente artículo, a la luz de la crítica levinasiana a la metafísica occidental, se pone en cuestión rendimiento político efectivo de tal triunfo.

Palabras clave: Totalidad, Evasión, Lévinas, Museo de la Memoria y los Derechos Humanos.

\section{Abstract:}

The incorporation of Pinochet in the last temporary exhibition of the National Historical Museum of Chile "Children of freedom. 200 years of independence" made possible a new 
irruption of memory in the present. The public debate that it raises was characterized by the media as a battle between emblematic museums because the Museum of Memory and Human Rights, together with other actors, accuse the former of transgressing the ethical framework of Human Rights and Human Right and transgress itself in it. The latter triumphs in hegemonizing the field of the recent past, constituting its logical structure as a legitimate mode of representation. In the present article, through the the Levinasian critique of Western metaphysics, the effective political performance of such triumph is put into question.

Keywords: Totality, Evasion, Lévinas, Museum of Memory and Human Rights, National Historical Museum.

\section{Introducción}

El exterminio sistemáticamente organizado por parte del Estado Alemán a ciertos grupos, especialmente judíos, durante la Segunda Guerra Mundial se ha estabilizado en la memoria social como un Crimen contra la Humanidad. En la Declaración Universal de los Derechos Humanos que deviene de esta catástrofe (1948), se establece el derecho fundamental a la vida como un derecho universal y cosmopolita. Lógica con la cual se ha desarrollado una cultura de los Derechos Humanos (DDHH) que bajo la consigna de Nunca Más, expresión utilizada originalmente por los sobrevivientes del Gueto de Varsovia (Horestein \& Silber, 201I), aspira a comprometer a otros en un discurso ético acerca del mundo que compartimos. Tal como lo expresara Adorno, Auschwitz inaugura un nuevo imperativito categórico: "Hitler ha impuesto a los hombres' un nuevo imperativo categórico para su actual estado de esclavitud: el de orientar su pensamiento y su acción de modo que Auschwitz no se repita, que no vuelva a ocurrir nada semejante” (Adorno, 1973, p. 358).

\footnotetext{
${ }^{1}$ Se ha decidido no modificar las citas originales de los autores en los que se utiliza el término "hombre" en un sentido amplio refiriendo a la humanidad en general. Sí, en aquellos párrafos donde se parafrasea los autores citados, se modificó hombres en sentido amplio por ser/es humano/s, humanidad o término similar no generizado.
} 
Tal imperativo se ha universalizado como prisma privilegiado para observar las atrocidades donde la memoria es un nuevo momento de la ética.

En ese marco, las Comisiones de Verdad (mecanismos extrajudiciales de investigación sobre esta tipología de crímenes) sugieren construir museos de la memoria que no sólo contribuyan a la reparación simbólica de las víctimas, sino que propongan una reflexión que sirva a las nuevas generaciones para reorientar el pensamiento y construir un presente (y futuro) de respeto irrestricto a la dignidad de las personas. Así lo declara en su Misión y Visión institucional el Museo de la Memoria y los Derechos Humanos de Chile $(\mathrm{MMDH})$, que surge a partir de las recomendaciones establecidas en el Informe de la Comisión Rettig (1992). Desde su inauguración en 2010, ha sido objeto de controversias. Mauro Basaure (2017) caracteriza dichas controversias en 3 fases. Una primera fase de 'neutralización de la memoria' que luego da paso a una primera formulación de 'crítica contextualizadora' (necesidad de antecedentes que expliquen las violaciones a los derechos humanos en el período 1973-1990) entre 2007 y 2010 en contextos de la proyección y construcción del museo. Una segunda fase, que adquiere su momento más álgido en 2012, se reformula la crítica contextualizadora, según Basaure, de una manera más sofisticada poniendo el foco en la función pedagógica del Museo. Para que se pueda aprender de la historia, versa la crítica, es necesario conocer la relación causal entre antecedentes y consecuentes. No para que los primeros justifiquen a los segundos sino para estar alerta a signos presentes de contextos similares. En una tercera fase (20I22016), la crítica al MMDH demanda la inclusión de grupos que observan sus derechos vulnerados y que tienen la expectativa de ser reconocidos de manera oficial al ser representados en este espacio. Ante tales críticas el Museo se resiste con insistencia apelando a la forma de memoria que lo constituye. Siguiendo a Basaure (2014), la forma lógica de contextualización que subyace a la crítica de Krebs presenta dificultades lógicas y morales, principalmente porque no permite desligarse de una justificación indirecta de la violación de los $\mathrm{DDHH}$, pues subordinaría el valor de los $\mathrm{DDHH}$ al valor del orden institucional. Aquello que no hay que repetir queda instalado en el conflicto social y 
quiebre del orden (los antecedentes) y no en la deshumanización y el crimen. Siendo que no existe ninguna necesidad histórico-causal entre el clima de beligerancia y conflicto y las atrocidades ocurridas durante dictadura (Basaure, 2014, p.173).

Si bien ante tal controversia el MMDH se resiste con insistencia a reivindicar su función socio-integrativa (de cohesión moral) antes que su función cognitivo-explicativa, lo cierto es que, las condiciones de posibilidad para las violaciones se los DDHH en Chile no parecen superadas del todo. No me refiero con ello al quiebre institucional ni al contexto de guerra fría, sino a los sentimientos nacionalistas frente a las recientes migraciones, la continua justificación de las clases dominantes al uso de la violencia por parte del Estado ${ }^{2}$, el tratamiento represivo del conflicto en el Wallmapu, por nombrar algunas problemáticas nacionales (sin describir el contexto global que mucho más nos dice). Fenómenos como los mencionados dan cuenta de que, pesar de la universalización de la Ética de Nunca Más en nuestros museos, la barbarie moderna persiste.

En este contexto, a comienzos del año 2018 se abre una nueva polémica que reflota algunos debates anteriores, a la vez que incorpora nuevos ejes de discusión y nuevos actores en lo que el periódico The Clinic titularía como una "Batalla entre emblemáticos museos”3. En el marco de la celebración del Bicentenario de la firma de la Independencia (2018), el Museo Histórico Nacional de Chile desarrolló una propuesta museológica inédita. Se abordaría durante el presente año nuestra historia política, reflexionando en torno a los tres conceptos que articulan el ideario de la Revolución Francesa -Libertad, Igualdad y Fraternidad- con el objetivo de historizarlos, es decir, develar sus interpretaciones y usos contingentes a lo largo de los últimos dos siglos. Esto a través de tres exposiciones temporales, cada una centrada en un concepto. La primera (y única en

\footnotetext{
${ }^{2}$ Resultados Primera Ola, Estudio Longitudinal Social de Chile (ELSOC). Módulo 1: Cohesión Social y Migración Notas COES de Política Pública N¹. ISSN: 0719-8795. Santiago, Chile.

3 http://www.theclinic.cl/2018/05/08/la-batalla-emblematicos-museos-provoco-una-imagen-una-frasepinochet/ Recuperado el 20.06.2018
} 
desarrollarse) fue la titulada, en alusión al relato que realizase Benjamín Vicuña Mackenna en sus diarios de viaje siendo embajador, "Hijos de la Libertad"4. Inaugurada el 5 de abril de 2018, dicha muestra consideraba la influencia del ideario emancipatorio en la gestación del proceso independentista pero también buscaba relacionarlo con las consecuencias tangibles de los procesos políticos en nuestra experiencia cotidiana como ciudadanos. Mediante este ejercicio el equipo curatorial se proponía historizar, es decir presentar el carácter contingente de cada uno de estos conceptos, y a la vez explorar modos de poner en tensión al museo como institución disciplinar en términos foucaultianos.

Pero esta pertinente apuesta museológica que fisuraba la significación homogénea de la nación y excedía el ritual conmemorativo, fue abortada a un mes de su inauguración. El novel Ministerio de las Culturas, las Artes y el Patrimonio estableció su clausura y, finalmente, de la trilogía en su totalidad, además de la destitución (solicitud de renuncia) de su director, Dr. Pablo Andrade. El detonante para dicho aborto fue la circulación en redes sociales (RRSS) de un recorte fotográfico que, descontextualizado de su entorno museográfico, advertía sobre la inaceptable inclusión de Augusto Pinochet en un espacio dedicado a la "incuestionable y sagrada" idea de libertad dentro de un museo que comprenden como templo. La imagen del dictador con banda presidencial junto a un extracto del discurso pronunciado en octubre de 1973: "La gesta del II de septiembre incorporó a Chile en la heroica lucha contra la dictadura marxista de los pueblos amantes de su libertad". La imagen no tardo en viralizarse y convertirse en una crítica masiva y legitimada por actores tan relevantes como el MMDH y el Instituto Nacional de Derechos Humanos (INDH) lo que provocó reacciones inmediatas en las autoridades que se vieron excedidas por la polémica. Como indican Estefane y Thieleman (2018), la nueva institucionalidad cultural mostraba su incapacidad de procesar lecturas disonantes

\footnotetext{
${ }^{4}$ Vicuña Mackenna dice “A esta especial i casi aislada posición geográfica, i a su formación montañosa, han atribuido a la par los historiadores i naturalistas, el amor a la libertad e independencia que muestran sus hijos, sentimientos que parece común a los pueblos que viven por si mismos, i para si mismos..." Citada por el curador principal Luis Alegría en $\quad$ El $\quad$ Mostrador $\quad$ 06-04-2018 https://www.elmostrador.cl/cultura/2018/04/06/exposicion-hijos-de-la-libertad-en-museo-historico-nacional/ Recuperado el 20-06-2018.
} 
respecto al consenso en torno al pasado reciente y, el MHN, su incapacidad de procesar la controversia y, sobre todo, la acción de estos nuevos públicos (no visitantes) virtuales.

En el debate dado en medios de prensa escrita y digital, para buena parte de los actores, un museo (a menos que sea de arte contemporáneo) no debe arriesgarse a provocar reflexiones, emociones y por tanto potenciales conflictos, sino ceñirse a una pauta oficial hegemónica pues estos "no se mandarían solos” (Joignant, 2018). El peligro de no transmitir la versión hegemónica sería que el MHN es una "entidad pública que expone la historia de nuestro país a un público amplio y no experto. Tratándose además de uno de los museos más visitados del país, tanto por escolares como por extranjeros, la cuestión es todavía más delicada" (Garate, 2018). Y, a pesar de que en su mayoría los actores no visitaron la muestra y basaron su opinión en la fotografía circulante y sus supuestos latentes acerca de lo que un museo de historia debe hacer, diagnosticaron el hecho como un atentado a la primacía de los DDHH como marco ético (Estévez, 20I8; Basaure, 20I8).

Ante esto el ministerio entonces ordena la clausura de la muestra y de la trilogía completa desabasteciendo de exposiciones temporales al MHN por el resto del año en curso e impidiéndonos la reflexión democrática en torno a tales ideas en dicho espacio. Además de promulgar la construcción de un futuro, y controvertido, museo (o sala) de la Democracia anexo a lo que será un nuevo guion para el MHN.

Triunfa la demanda del MMDH, el MHN queda condenado a la reproducción del discurso oficial de manera acrítica y el MMDH legitima su hegemonía frente a los límites del discurso respecto a un cierto periodo de la historia de la nación. Sin embargo, como indica Luis Alegría (2018) dicha victoria es un triunfo de tipo "pírrico", en el sentido clásico. Es decir, una victoria que se consigue con muchas pérdidas, tantas que incluso tal victoria puede terminar siendo desfavorable para dicho bando. Es esta la hipótesis que, a la luz de la crítica levinasiana a la metafísica occidental, quiero levantar. Son, siguiendo a Emmanuel Levinas, las condiciones propias de la racionalidad y política occidental las que contienen la posibilidad de la barbarie moderna que intenta evitarse (Lévinas, 1934; 
Agamben, 1998; Esposito, 2006), por lo que la aspiración a construir una cultura democrática, bajo la lógica hegemónica del MMDH, es problemática. ¿Por qué? Porque procura fijar, cerrar y universalizar una particular concepción de Verdad, Memoria, Política y Humanidad, unidireccionalmente desde un "saber experto", y no de mantener aperturas respecto a la interpretación del pasado y la construcción del futuro. En definitiva, al refirmar el "monopolio narrativo de la memoria" desde esta lógica el MMDH condena a los procesos de memoria a reproducir la latente posibilidad de Auschwitz que busca eliminar.

Para plausibilizar esta incipiente hipótesis respecto a la controversia, describiré el proceso de apertura buscado por el MHN y rebatido por el MMDH. Luego exploraré la crítica a la racionalidad occidental y los principios político-filosóficos que de ella derivan, principalmente desde las tesis que Lévinas (1934, 1935, 196I) y Agamben (1995) levantan a propósito de la Shoa, para mostrar la estrecha relación entre el piso epistemológico desde el cual el MMDH obtiene su victoria en esta contienda. Abriendo finalmente preguntas para lo que parece ser una nueva fase de controversia en torno a la memoria.

\section{“Hijos de la Libertad”, la museología vencida}

Desde el Museion de Alejandría, el "templo de las musas" ha cruzado saber, memoria y poder en una red compleja, sin embargo, es en el contexto moderno, caracterizado por la distribución del poder en distintas esferas o campos, que emergen los Museos Nacionales. El historiador del arte Douglas Crimp en su ensayo Sobre las ruinas del museo (1993), siguiendo a Michel Foucault (1998), da cuenta de cómo occidente comenzó a experimentar una transformación en sus mecanismos de poder distribuyéndose en una serie de instituciones disciplinarias que interpretan y organizan la experiencia social moderna y el rol que los museos juegan en ello. Indica que "existe otra institución de confinamiento (el museo) y otra disciplina (la historia del arte) que se prestan a análisis en los términos de Foucault” (Crimp 1993, p. 45). Mas que instituciones de confinamiento, sino instituciones de exhibición que forman un complejo de relaciones disciplinarias y de 
poder que el sociólogo Tony Bennett (1995) denomina el "complejo expositivo". Bennett afirma que al poner en circulación representaciones, objetos y cuerpos en el espacio público, logran inscribir normas y jerarquías legitimadas en función del constructo de nación. La influencia del complejo expositivo no radica en la imposición desde un poder soberano entendido como dominación directa, sino a través de lo que Gramsci llama consenso (Said, 1978, p.26). La estabilización de ese consenso a través de la performatividad del complejo expositivo es aquello que las exposiciones universales, las ferias mundiales y luego los museos, movilizan convirtiendo todo lo ahí coleccionado y exhibido en objeto de conocimiento científico.

Durante la segunda mitad del siglo $X I X$ y la primera mitad del $X X$ se llevaron a cabo muchas exposiciones de este tipo que organizaba en pabellones

"una serie de clases y subclases que iban en orden ascendente desde materias primas de la naturaleza, varios productos manufacturados y dispositivos mecánicos, hasta las formas más 'elevadas' de arte aplicado y bellas artes” (Davison en Bennet, 1995) para estar a disposición de un amplio público redefiniendo el "estatus del sujeto observador" (Crary, 2008, p. I7).

La Exposición del Coloniaje en Santiago de 1873 es una de las experiencias fundadoras del complejo expositivo en Chile. Esta exposición combinó pedagogía, historia y entretenimiento y contó con un total de 600 objetos divididos en doce secciones. El interés de Vicuña Mackenna era que la asistencia no se restringiera a las clases sociales altas, sino que las clases bajas se convirtieran también en espectadores disciplinados. Pues, al igual que las exhibiciones europeas, las clases populares se integraban para propiciarles una pedagogía moral. En sus palabras, su objetivo era que "un suficiente número de prendas valiosas cautivarían la atención concienzuda de las jentes de estudio i despertar los apetitos de curiosidad del vulgo" (Vicuña Mackenna, 1873a, p. 347). En 1910 esta fórmula se replica con la Exposición Histórica del Centenario, la que cuenta no solo con la recaudación de un número de objetos mucho mayor sino con un mayor éxito de público. 
Se reúne el acervo de estas distintas experiencias y se solicita al gobierno la firma del decreto que crearía al Museo Histórico Nacional volviendo esta tecnología permanente en I9II.

A grandes rasgos, esta es la herencia material y discursiva de nuestros museos nacionales, el de historia en particular, hasta la actualidad. Hecho que ha sido deconstruido y observado críticamente por expertos en el mundo desde la realización de la Mesa Redonda de Santiago de Chile en 1972, conferencia del International Council of Museum (ICOM). Dicha conferencia dio inicio a una serie de planteamientos teóricometodológicos que transformaban el modo tradicional de comprender el museo materializándose en Ecomuseos y Museos Comunitarios entre otras experiencias definidas en dicha conferencia como proyectos de Museo Integral. Hugues de Varine, museólogo participante de esta mesa explica que

"consciente de la necesidad de abrir el museo tradicional, afirmo que el museo debía considerarse no un edificio, sino una región, no una colección sino un patrimonio regional y no un público sino una comunidad regional participativa. De ahí el triángulo de soporte de la nueva museología: territorio-patrimoniocomunidad” (Bolaños, 2000, p. 293).

Este proceso transformador en la museología internacional, iniciado en nuestra capital, no pudo desarrollarse en plenitud en nuestro país principalmente debido a la dictadura que irrumpe al año siguiente. Ésta, mientras reprime la acción y creación colectiva, promueve la creación de patrimonio como elemento esencial para un rediseño forzado del pacto social (Brunner, 1988). El MHN entonces sirvió, entre otras políticas patrimoniales (monumentos, fiestas nacionales, folklor, etc.), para la refundación simbólica del régimen dictatorial entregándole legitimidad y adhesión social además de habituación a las pautas de un nuevo orden autoritario y, con ello, perpetuó la estructura disciplinar de la 
institución museal decimonónica. A 40 años de la Mesa Redonda de Santiago, la museología en Chile parecía remontar el camino crítico perdido. El MHN en particular inicia un proceso lento y tímido de reflexión interna que comienza a manifestarse con su Exposición Aniversario "I00 años, 1000 historias 1911-20II”. En ella se dio cuenta del origen de sus colecciones y las políticas de patrimonialización que lo han configurado a lo largo de un siglo, además de sus modos de operación (funcionamiento interno de la institución) actual. Develando, sin criticar explícitamente, su constitución material y discursiva asociada a lo que denominamos recién como complejo expositivo. Dicho trabajo curatorial constituye la primera vez que un museo en Chile se sitúa a sí mismo como objeto de exhibición y declara con ello que un museo performa en su ejercicio constructivo/expositivo lo que un museo es. Este ejercicio tuvo alto impacto en los funcionarios, los cuales comenzaron a impulsar coloquios, seminarios, recorridos comentados, foros y exposiciones donde se ensayasen ángulos posibles para una actualización del museo. Junto con los diálogos para la construcción de un nuevo guion del año 2013, que surgieron tras la resolución judicial que otorga propiedad al museo (y no a Correos de Chile) del predio contiguo, se realizó el coloquio Musealidades Mestizas el año 2015, los recorridos comentados llamado Objeto y Discurso del año 2016, entre otras actividades que convocaron una multiplicidad de expertos y a la sociedad civil. Dicho proceso buscó entender a los museos como maquinarias implicadas en la experimentación/formación de capacidades cívicas, pero proyectándose como un laboratorio cívico distinto al decimonónico como indica Bennett (2005). Un laboratorio de código abierto, con mecanismos museales no clausurados (Pinochet Cobos, 2016), donde la co-construcción del imaginario social sea dinámica, contextual e híbrida (Meirovich, 20II; 20I5). Así lo declara el texto El Museo Mestizo del presente año con el cual se fraguase un nuevo proceso constituyente del museo de cara a su ampliación física. "El pensamiento mestizo - indica el escrito- puede comprenderse en la medida en que se abandonen categorías absolutas y cerradas y se incursione en los espacios intermedios y difusos en donde estas se construyen" (Andrade et.al., 2018, 18). Para explicar de manera más precisa esta opción museológica, el texto mencionado recurre al concepto Ch'ixi con 
el cual la socióloga boliviana Silvia Rivera Cusicanqui intenta diferenciarse de la noción de hibridez de Néstor García Canclini. Hibridez, argumenta Rivera, es una metáfora genética de cuya mezcla saldría una tercera entidad fusionada e inédita, pero estéril, como la mula. Por ello, propone reemplazar lo híbrido por lo ch'ixi como coexistencia en paralelo de múltiples diferencias culturales que no se funden, sino que se relacionan de forma contenciosa y complementaria simultáneamente (Rivera, 2010). Esta palabra aymara, literalmente refiere a un color producto de la yuxtaposición en pequeños puntos o manchas que se confunden para la percepción sin nunca mezclarse del todo. Un color gris, ch'ixi, es blanco y no es blanco a la vez, es blanco y también es negro, su contrario, se confunde.

Es en este contexto de reflexión y reorganización que emerge la exhibición temporal llamada "Hijos de la Libertad. 200 años de Independencia" la cual no se enfocaba en el periodo dictatorial, sino que lo incorporaba en una historia política de larga data. Junto con dicho contenido, esta exposición es la primera en ensayar el sistema co-curatorial y la primera en incorporar diversas áreas del quehacer museológico en la elaboración del guion (departamento educativo, conservación, documentación e historiadores). Independiente de la evaluación de sus resultados, la cual no pudo medirse con seriedad debido al cierre, la muestra buscaba transgredir límites propios de la musealidad moderna e incluso de la racionalidad occidental que se expresa en la concepción homogénea y ahistórica de sus conceptos políticos y la clausura representacional.

\section{EI Museo de la Memoria y los Derechos Humanos, la museología vencedora}

El Museo de la Memoria y los Derechos Humanos de Chile se inaugura el año 2010, como proyecto culminante de la política reconciliatoria y oficialista de la Concertación. Como un vestigio monumental de la existencia de una "exitosa" política de administración del pasado reciente respecto de la violación de los DDHH durante la dictadura (Collins, et. al. 2013). Michelle Bachelet, primera mujer presidenta de Chile y afectada directa de la dictadura, es quien da inicio simbólico, de la mano del museo, al fin de la transición que, 
tras su mandato, recibiría al primer presidente de Derecha electo democráticamente postdictadura.

La obra arquitectónica creada para albergar el museo en cuestión es la metáfora con la que las políticas de memoria chilenas se presentan ante el público nacional e internacional. Como dice Nelly Richard,

"El afuera del Museo de la Memoria ha sido revestido de placas de cobre como símbolo integrador que alude a la 'identidad nacional', cuyo trasfondo de chilenidad remarca lo que nos une a todos frente a los eventuales riesgos de división políticas y confrontación ideológica de la historia contingente. El Museo de la Memoria se destaca, adentro, por una arquitectura de vidrios que proyecta luminosidad e irradia nitidez a través de superficies abiertas que parecerían querer erradicar todas las sombras y los claroscuros del recuerdo tenebroso de los años de la represión militar y los secretos vergonzosamente protegidos en torno a sus crímenes" (Richard, 2010, p. 265).

Una vez dentro, el museo realiza tres declaraciones de suma relevancia como introducción o contextualización al recorrido. Primero, sobre una estructura en obra de un mapa de Chile que hace de soporte, una serie de señales marcan otras experiencias de patrimonialización de la memoria con la que el museo explicita que no es la única, ni la primera, sino la oficial. Segundo, al ingresar al Hall principal, el visitante se enfrenta con un mapamundi que retrata distintas geografías donde el Estado ha perpetrado crímenes de lesa humanidad contra su población (Sierra Leona, Yugoslavia, Guatemala, Bosnia, entre otras). Es así como el recorrido a continuación se contextualiza en el marco de la violación a los DDHH como problema mundial abstracto, donde Chile sería un caso local dentro de una situación más amplia. Tercero, con una museografía tradicional (por no 
decir anticuada), que contrasta con el resto de la exposición, exhibe en una vitrina móvil una copia de los informes de las Comisiones de Verdad nacionales (Rettig, 1998 y Valech, 2003). Con ello, delega la responsabilidad de ser narrador oficial del guion a tales informes, mientras los legitima como verdad objetiva e incuestionable.

De lleno en el recorrido, comienza una emotiva y dolorosa experiencia de pérdida de los derechos en la zona "II de septiembre" que culmina en la zona "El dolor de los niños". El primer piso en general se caracteriza por buscar remecer emocionalmente al visitante, que éste logre empatizar con la experiencia dolorosa y confusa del Golpe, la tortura, ejecución y desaparición. La escalera amplia e iluminada que se sube para acceder a la segunda parte de la muestra permite ir calmando ese dolor a medida que emerge el deseo de Verdad y Justicia, título de la sala que recibe al visitante. Ahí se homenajea a los personajes e instituciones "heroicas" de la época. El segundo piso, a diferencia del anterior, se caracteriza por mostrar de manera lineal una narrativa triunfalista respecto a cómo Chile vence la dictadura. Irrumpe en ello la zona “Ausencia y Memoria”, la cual los guías suelen presentar como el "corazón de la muestra" (Catálogo de la exposición permanente, p.70) que corresponde al espacio central, justo arriba de la primera sala (I I de septiembre). Es una especie de balcón transparente que hace de mirador privilegiado para el muro de fotografías identitarias de los desaparecidos. La sala es acompañada por una "velatón" que nos acerca a la experiencia popular compartida de la ausencia durante estos años. Es el único espacio dentro del recorrido destinado a la reflexión no cognitiva. Si bien, cuenta con un tótem digital que permite indagar en las historias de vida de los representados en el muro (obtener conocimiento de sus vidas empíricas), es un espacio para la experiencia de ausencia y duelo, para conectar con lo inmensurable de esa ausencia.

Luego, la sala "Lucha por la Libertad" y, por último, el "Retorno a la Esperanza". Esta zona cuenta con tres sectores, la cultura, el plebiscito y el fin de la dictadura. Es decir, la cultura en dictadura, en este contexto, está ya inscrita en una retórica del triunfo invisibilizándola como espacio de construcción de estigmas y sentidos comunes donde se 
produce el Homo Sacer. Para, finalmente, cerrar el recorrido con el discurso de Patricio Aylwin en el Estadio Nacional. Como si la construcción o reconstrucción democrática se realizara en sólo un acto, como si el fin de la dictadura fuese sinónimo del retorno a la democracia. Tanta es la relevancia del plebiscito, que una pantalla que transmite las campañas televisivas del Sí y el NO, inundan auditivamente, todo el final del recorrido. Con ello, la experiencia de cierre es total y, el paso siguiente, el espacio de reflexión para “Nunca Más” pierde sentido pues ¿si la democracia fue recuperada en 1990 qué es aquello que no hay que repetir? ¿Queda trabajo por hacer? ¿Soy yo, el espectador, responsable de ello?

En tal contexto museológico, la sala "Nunca Más" se proyecta como un espacio distinto y separado del recorrido anterior. Está pensada como epílogo de la muestra permanente; un lugar más allá del cierre de la exposición de los hechos ocurridos entre 1973-1990. Según Ricardo Brodsky, ex director del MMDH, el objetivo de la sala es iniciar la reflexión en torno a icómo comprometernos constantemente con la universalidad/particularidad del ser humano? El desafío es dejar en la experiencia del visitante la sensación de responsabilidad en la co-construcción de un mundo compartido en medio de la diversidad; de posicionarse como protagonistas de la construcción política y cultural que pone como horizonte los $\mathrm{DDHH}$. Constituye, museográficamente, un salto reflexivo debido a que todo el recorrido se basa en la exposición de hechos narrados de manera lineal, unidireccionalmente, sin contexto previo ni posterior a los hechos conmemorados, construyendo un espectador poco activo. Quizás es por la dificultad de conectar dos espacios planteados en lógicas diferentes que la Sala "Nunca Más” ha permanecido vacía desde el año 2015. La experiencia de visita es de ausencia de una construcción de relato histórico acerca de nuestro presente y nuestro futuro. El "Nunca Más" que se pretende queda agotado en el triunfo del NO y la entrega del informe Rettig. Cabe preguntarse ¿Cuáles son las consecuencias de la dictadura en la sociedad general? ¿Cuáles serían las condiciones de posibilidad presente para la repetición de los hechos? 
Este vacío lleva nuestra mirada inevitablemente al ventanal, que se encuentra a la izquierda del observador, en donde es posible ver la zona de "Ausencia y Memoria", velada por el vidrio. Como un fantasma que nos recuerda que para construir una nueva comunidad política hay que volver la mirada a la memoria pues ésta, está en constante construcción (Stern, 2010). El desafío de la Sala “Nunca Más” es simbolizar la experiencia narrada, de modo que permita proyectar un pasado negativo en un futuro legitimo con fuerza performativa, pero si nos atenemos a la exhibición en su conjunto la dificultad es mayúscula pues en ella se ha estabilizado una Verdad fáctica, una Política de consenso y reconciliación, una Humanidad universal esencial y una Memoria incuestionable. Mnemosine, la diosa de la memoria y madre de las musas queda encadenada al cuerpo. El futuro legítimo que aparece no logra exceder la racionalidad característica del pensamiento occidental que contiene la latente posibilidad de Auschwitz.

\section{Racionalidad occidental y totalidad, Mnemosine tiene necesidad de evasión}

Según la teoría clásica de la soberanía, el poder se caracteriza fundamentalmente por el derecho de vida y muerte, esto es, el derecho de hacer morir y dejar vivir ${ }^{5}$. En el siglo XIX, este derecho es complementado, pero también modificado por lo que Michel Foucault (1998) denomina biopolítica ${ }^{6}$, el poder de hacer vivir y dejar morir. Este autor, hace referencia a la definición aristotélica de ser humano para argumentar sobre este nuevo carácter moderno del ejercicio del poder, señalando que ésta última sería un cambio respecto de una arcaica concepción de política: "Durante milenios el hombre siguió siendo lo que era para Aristóteles, un animal viviente y además capaz de una existencia política; el hombre moderno es un animal en cuya política está puesta en entredicho su vida de ser viviente" (Foucault, 1998, p. 173). Esta distinción es utilizada

\footnotetext{
${ }^{5}$ Idea que Foucault grafica magistralmente con el relato de la ejecución publica de Damiens, en Vigilar y Castigar, publicado en 1975. ${ }^{6}$ Según Roberto Esposito, no es Foucault quien acuña el término, pero si es gracias a su desarrollo conceptual
que adquiere relevancia teórica.
} 
por Aristóteles para establecer qué es una comunidad política (qué se encuentra dentro y qué se encuentra fuera de la polis). Dentro se encuentra la bíos (una forma de vida cualificada) y la zoé (la mera vida natural u orgánica) es excluida de ella e incluida en el ámbito del oikos (espacio privado). La política surge precisamente a través de esta exclusión. Sólo en el espacio común (la polis) el ser humano hace pleno uso del lenguaje (lógos) y no simplemente de la voz (phone). Es decir, en la comunidad política aristotélica es donde se encuentran los "propiamente humanos" y son ellos quienes se regulan a través de la igualdad y la justicia. Pero esto no responde sólo al espíritu de la antigüedad, en la modernidad, las teorías contractualistas reproducen esta exclusión. En la guerra de “todos contra todos" que se daría naturalmente para Hobbes (I65I), los individuos se comprometen a ceder su voluntad a un soberano y así instaurar el estado civil compuesto de leyes con poder coactivo. Lo natural permanece fuera del orden de lo legal. Así, desde Aristóteles, en cierto sentido, lo propiamente humano sólo es tal en el ámbito de la esfera pública.

Sin embargo, a través de la excepción, el derecho incluye lo excluido. Siguiendo a Carl Schmitt, Agamben considera que la excepción es la clave para pensar la estructura de la soberanía. El soberano se encuentra dentro, pero a la vez fuera del orden jurídico porque puede decidir cuando ese orden puede suspenderse. Paradojalmente él, está autorizado por la ley a ponerla en pausa. En estado de excepción, la ley no pierde su vigencia, sino que se "aplica desaplicándose”. Es decir que lo no jurídico es también parte de la ley. Por eso es que para él,

"La tesis foucaultiana debe, pues, ser corregida o, cuando menos, completada, en el sentido de que lo que caracteriza a la política moderna no es la inclusión de la zoé en la polis, en sí misma antiquísima, ni el simple hecho de que la vida como tal se convierta en objeto inminente de los cálculos y de las previsiones del poder estatal: lo decisivo es, más bien, el hecho de que [...] el espacio de la nuda vida que estaba situada originariamente al margen del orden jurídico, va 
coincidiendo de manera progresiva con el espacio político, de forma que exclusión e inclusión, externo e interno, bíos y zoé, derecho y hecho, entran en una zona de irreductible indiferenciación” (Agamben, 2003:18-19).

Para Agamben, es ahí donde se produce una vida a la que cualquiera puede dar muerte impunemente, pero que a la vez es insacrificable, es decir, una vida expuesta a la muerte cuya eliminación no se considera homicidio legal ni sacrificio ritual: la nuda vida del Homo Sacer. $Y$ si existe un espacio que pueda ser considerado paradigmático de la biopolítica moderna, ese es Auschwitz, debido a que "el campo de concentración es el espacio que se abre cuando el estado de excepción empieza a convertirse en regla” (Agamben, 2003, p. 215), y esto, para el filósofo italiano, no es una transformación sino una radicalización de la estructura política occidental originaria.

Siguiendo a Reyes Mate (2003), el hilo conductor que lleva a Emmanuel Lévinas desde la crítica al hitlerismo a la crítica a la racionalidad occidental, es el propio de la biopolítica. En su texto Algunas reflexiones sobre la filosofia del hitlerismo de 1934, Lévinas argumenta que el hitlerismo ha despertado sentimientos elementales que han radicalizando la experiencia del cuerpo, poniéndolo como centro de la vida. La sangre y la tierra (y no el logos) es lo que define una comunidad y sus relaciones políticas, en la filosofía del hitlerismo. La identificación con el cuerpo no permite distancia alguna, el autor grafica ésto con la idea de estar "encadenado al cuerpo". El hitlerismo es esa expresión moderna de un mal elemental que consiste en el encerramiento del ser humano en el cuerpo y en el tiempo, condición de lo irreparable (Lévinas, 200I, p.8).

Para llegar a tales conclusiones, Emmanuel Lévinas realiza un diagnóstico fenomenológico de su época recurriendo a tres categorías fundamentales: nausea, vergüenza y evasión. Es en 1935, con el texto De la Evasión donde desarrolla estos conceptos que revelan lo político en su filosofía. Explica que, el ser humano, totalmente identificado con su cuerpo, está poseído por la náusea que le ocasiona la lejanía de tierra firme. La embarcación es parte de nuestra flotación solitaria, experiencia existencial de abandono en la nada y, en 
ese momento máximo de peligro, crece la "salvación", la imperiosa necesidad de evadirse de aquella experiencia de imposibilidad de cambio, de que no hay nada que se pueda ya hacer. De ahí viene la vergüenza de no poder ocultarnos a nosotros mismos nuestra propia desnudez (Mate, 2003, p.60). El autor se centra en el fenómeno de la evasión, pues éste pretende romper el lazo entre la existencia que tenemos y el existente que somos, lazo o confusión que es la causa de la náusea y de la vergüenza. Lo que caracterizaría al hitlerismo es entonces, para Lévinas, la ausencia del estado de evasión: los sujetos del hitlerismo no lo viven como un malestar (nausea o vergüenza) y, al no conocer el sufrimiento del encadenamiento, el encierro se constituye en categoría espiritual central.

Si bien Lévinas se inscribe en un movimiento de pensamiento, representado por la filosofía de Heidegger, empeñado en rescatar la facticidad y por ende la importancia del cuerpo, en vez de generar de ello un principio de identidad como su maestro, lo que genera es un principio de alteridad. El origen de la barbarie Nazi estaría alojado en la latencia del mal elemental que se ha instalado en la ontología del Ser preocupado de ser, un Ser que tiene que ser sólo sus modos de existencia. Para Lévinas, el existente no puede estar gobernado por la existencia misma y por ello acuña el concepto de excedencia. Esta idea, junto con la experiencia en "carne propia" de la Shoah, lo lleva a radicalizar su enfrentamiento intelectual, ya no sólo contra la fenomenología heideggeriana a la base del hitlerismo, sino contra la metafísica occidental que se desentiende de los objetos que la conciencia no trae a presencia a través de la representación.

En su obra Totalidad e Infinito, de 196I, Lévinas se enfrenta a la dialéctica hegeliana argumentando que ésta produciría una totalidad en donde la diferencia no es diferencia, pues queda siempre incluida en el todo. No permite la posibilidad de un exterior y todo se vuelve objetivable. El autor indica que "la fenomenología hegeliana -en la que la conciencia de sí es la distinción de lo que no es distinto- expresa la universalidad del Mismo que se identifica en la alteridad de los objetos pensados (...) La diferencia no es diferencia, el yo, como otro, no es Otro" (Lévinas, 1997 citado en Castro, 2009, p.84). En 
palabras de Žižek, "el otro es bienvenido siempre y cuando su presencia no sea intrusiva, a condición de que no sea realmente otro" (201 I, p.l19).

La estabilización de saberes y sistemas universales no emerge con la modernidad, sino que tiene una larga trayectoria filosofía occidental. Para Lévinas, "Esta historia (la de la filosofía) puede ser interpretada como una tentativa de síntesis universal, una reducción de toda la experiencia, de todo lo que tiene sentido, a una totalidad en donde la conciencia abarca al mundo" (Lévinas citado en Castro, 2009, p. 83). Por ello es que el concepto de infinito es, para Lévinas, el único capaz de fisurar la totalidad. Siguiendo a Rosenzweig, Reyes Mate (2003) explica que más que el totalitarismo, la clave última de la barbarie moderna es la subyacente negación de la experiencia. Es decir, a la lógica de la idea se opone a la lógica de la experiencia, en cuanto separa lo singular del todo. Por ello, en la reducción del Ser al pensar, en el imperio de la lógica de la idea queda excluido lo singular, lo contingente, lo marginal y lo derrotado. En la creencia en una esencia originaria, dicho elemento esencial puede sustituirse por cualquier otro sin que exista ningún problema lógico (Mate, 2003). Por ello, explica tal autor, el miedo a que Auschwitz se repita es bien fundado, pues el Ser, siempre es cómplice de la barbarie debido a que, como ya se ha dicho, la ontología occidental conduce a la negación del Otro.

Para ensayar una vía de escape la ontología como fundamento de lo social (y lo político según Abensour), Lévinas imagina una conciencia pre-intencional entendida como receptividad pura. Lo originario del Ser, desde tal perspectiva, no sería una correlación entre conciencia y Ser (implícita en la intencionalidad) sino la diferencia entre mi Yo y el Yo del Otro. Lo originario sería ese espacio que aísla al humano del humano, y lo ético, aquello fundante de la sociedad, porque nos constituimos nosotros mismos a partir del Otro. Antes de la presencia interpelante del Otro somos pura existencia vacía, dice. En ese sentido, siguiendo a Lévinas, no se nace humano, sino que se adviene.

Tal argumentación le permite a Emmanuel Lévinas refutar también la hipótesis de Hobbes diciendo "No es seguro que al comienzo fue la guerra. Antes de la guerra estaban los 
altares” (Lévinas en Abensour, 2007, p. 170). Lo evidente del argumento de Hobbes, de la necesidad de mediar a través de la razón la violencia naturalizada de la guerra de "todos contra todos", se desmiente empíricamente con las Guerras Mundiales y la Shoah en particular. La pacificación gracias a un saber universal, promesa ilustrada, no se sostiene como fundamento de lo político después de Auschwitz. Una sociedad, cuya política se instala desde el principio de identidad, niega la alteridad, configurando un Estado que limita la violencia con violencia. Por ello Abensour indica que Lévinas pone sus esperanzas en la construcción del Estado desde un nuevo fundamento. El Otro donde se da una relación ética pre-política trae lo incalculable que, por no estar determinado, no puede oponerse a un Otro como igual. Desde tal perspectiva, Lévinas plantea una extravagante hipótesis: que la función del Estado no es limitar la violencia (como la perspectiva hobbeseana), sino, limitar el infinito de la relación ética de responsabilidad para con el Otro. Tanto en Paix et proximité de 1984, como en entre otros textos posteriores al fin de la guerra, Lévinas se dedica a pensar el Estado y la Justicia. Abensour da cuenta de la reflexión con que éste filósofo construye modelos de Estado opuestos para pensar, metafóricamente, un Estado Justo construido desde la alteridad y no la identidad. Compara Roma con Jerusalén o, el Estado de César con El Estado de David (Abensour, 2005). El primero corresponde a la idea hobesseana de Estado donde la paz es por coacción a diferencia de la idea levinasiana donde la paz es por proximidad. El Estado de César está destinado a oscurecer el disenso, la diferencia, la asimetría y el Otro. El Estado de David, al no reducir lo político a la autodeterminación del Estado, se configura como un Estado más allá de éste. Ello implica que el Estado no pierde proximidad con aquello que lo excede: "La extravagante hipótesis que hace proceder el Estado de la proximidad original abre, por tanto, la vía a la crítica e incluso a la revuelta que lleva a invocar este origen extraordinario" (Abensour, 2005, p. 125).

En ese sentido es que la ética de Nunca Más, asociada a los DDHH como horizonte, tiene pocas posibilidades de probabilizar la no repetición. En la evaluación que hace Hannah Arendt respecto de la condición de los refugiados indica que 
“la concepción de los derechos humanos que descansa sobre la supuesta existencia de un ser humano como tal, se derrumbó en el instante mismo cuando aquellos quienes proclamaban creer en ella enfrentaron, por vez primera, a personas que habían perdido todas las demás cualidades y relaciones específicas, excepto su condición de humanos” (I958, p.297).

Tal como el homo sacer de Agamben, es decir, un ser humano reducido a la nuda vida. En una dialéctica de lo universal y particular, al modo hegeliano, cuando se priva a un ser humano de la identidad socio-política que da cuenta de su ciudadanía específica es cuando, simultáneamente, deja de ser reconocido o tratado como humano. Semántica que Baer (2012) recuerda cuando el diputado francés, Clermont-Tonerre, enunciase durante la Asamblea Nacional Francesa en 1789 “A los judíos como individuos todo, como nación nada”. ¿Qué sucede entonces con esta victoria del MMDH frente a los intentos de apertura del MHN?

\section{Consideraciones finales}

Como hemos visto, el MMDH provee "una concepción histórico-filosófica con cierto aroma hegeliano" (Basaure, 2014, p.I75) que termina por hegemonizar, fijar y expandir una particular concepción de Verdad, Memoria, Política y Humanidad en lugar de mantener aperturas, exterioridades y posibilidades de evasión.

El reclamo que llevó a la censura del MHN impidió la instauración de nuevas museologías. La "inaceptable" inclusión de Augusto Pinochet en museo comprendido como templo y su limitación imagen del mal radical juega un flaco favor a las políticas de memoria- 
Triunfa la demanda del MMDH, el MHN queda condenado a la reproducción del discurso oficial de manera acrítica, museo de la Democracia (modo de empate gubernamental) incluido. El ejercicio de la memoria debe proveer una reflexión en torno al futuro que se centre en lo irreductible del ser humano y lo irreductible de lo político. Como explica Gutiérrez, "Lo irreductible de lo político, su carácter indómito es precisamente esta resistencia a devenir sistema cerrado, en el que un principio de regulación y de limitación vendría desde sí. Dicho de otro modo, lo irreductible no es una noción de clausura sino de abertura hacia lo Otro" (Gutiérrez en Castro-Serrano, 2014, P 59). Invitar a las audiencias de los museos a imaginar una comunidad política que contenga su exceso, que permita actualizar inesperados horizontes de posibilidad colectiva, es la tarea. Porque un Estado

"nacido de la violencia, instalado para limitar esta violencia -eventualmente a través de la violencia- este Estado no conoce ninguna exterioridad al fenómeno de la violencia. Porque incluso la paz que instala, paz armada como aquella de los Imperios, reposa, más o menos sobre la violencia virtual” (Abensour, 2005 p. 185).

La memoria tiene necesidad de excedencia, el rendimiento de la museología contemporánea no está en representar lo inconmensurable sino proveer una vía de evasión a Mnemosine, el cómo, es algo que al menos el MHN por ahora no podrá seguir ensayando.

\section{Bibliografía:}

Abensour, M. (2005). La extravagante hipótesis. Revista de Filosofía, 61, 169-196. 
Adorno, T. (1973) Gesammelte Schriften, 6, 358

Agamben, G. (1998). Homo sacer. El poder soberano y la vida nuda. España: Pre-textos.

Andrade, P. (2018a). Hijos de la Libertad. 200 años de Independencia. Santiago: Museo Histórico Nacional de Chile.

Andrade, P. (2018b). El Museo Mestizo. Fundamentación Museológica y Disciplinar para el Cambio de Guion. Santiago: Museo Histórico Nacional de Chile.

Andrade, P. (2018c). Foro Representaciones de la historia reciente y perpetradores en museos del Estado: Límites, Desafíos y Dilemas. Organizado por el Centro de Conflicto y Cohesión Social (COES), Santiago.

Baer, A. (2012). Memoria de uschwitz y antisemitismo secundario ...y tres tesis sobre el prejuicio anti-judío en la españa actual. Constelaciones - Revista de Teoría Crítica.

Báez, C. y Mason, P. (2006). Zoológicos humanos. Fotografías de fueguinos y mapuche en el Jardin d'Acclimatation de París, Siglo XIX, Buenos Aires, Pehuén.

Basaure, M. (2014) Aprender críticamente de la historia, de la posibilidad de un diálogo al interior de la controversia en torno al Museo de la Memoria y los Derechos Humanos. En Bustamante, G. et al. La agonía de la convivencia: violencia política, historia y memoria. RIL Editores, Santiago.

Bastías, Malena (2016). Del relato oficial a la recepción de los visitantes: análisis de la puesta enescena del pasado reciente en el Museo de la Memoria y de los Derechos Humanos de Chile. Arrieta Urtizberea, I. Lugares de memoria traumática. Editorial de la Universidad del País Vasco, Bilbao.

Bennett, T. (1995). The Birth of the Museum: History, Theory, Politics. London and New York: Routledge. 
Bolaños, M. (2000). La memoria del mundo, 100 años de museología 1900-2000. Editorial Trea. Madrid, España.

Brunner, J.J. (1988). Un Espejo Trizado. Ensayos sobre cultura y políticas culturales. Chile: Flacso.

Castro, B. (2009). Las posibilidades del Sentido y la Alteridad Radical: un recorrido arqueológico por el pensamiento de Lévinas. Revista Internacional de Filosofía, n 48, 81-96

Crimp, D. (1993). On the Museum's ruins. Cambridge, Mass., MIT

Déotte, JL. (1998) Catástrofe y olvido: las ruinas, Europa, el museo. Editorial Cuarto Propio. Santiago.

Esposito, R. (2006). Bíos. Biopolítica y filosofía. Buenos Aires: Amorrortu.

Foucault, M. (1998). Historia de la sexualidad I. La voluntad de saber. México: Siglo XXI editores.

Gutiérrez, C. (2009). Para una fenomenología de lo social en Emmanuel Lévinas. En Bonzi, P. y Fuentes, J.J. (Eds.), El énfasis del infinito. Esbozos y perspectivas en torno al pensamiento de Emmanuel Lévinas. Santiago de Chile: Universidad de Chile y Barcelona: Anthropos.

Horestein, M., \& Silber, D. (2011, marzo 25). Día de la Memoria, la Verdad y la Justicia: No es una suma de casualidades. Diario Clarín.

Krebs, M. (2012) «El Museo de la Memoria puede mejorar su calidad pedagógica» La Tercera Edición Impresa. Recuperado 20 de julio de 2016, a partir de http://diario.latercera.com/2012/07/12/01/contenido/cultura-entretencion/30-113612-9-magdalenakrebs-el-museo--de-la-memoria-puede-mejorar-su-calidad-pedagogica.shtml

Lazzara, M. (2011): "Dos propuestas de conmemoración pública, Londres 38 y el Museo de la Memoria y los Derechos Humanos Santiago de Chile", A contra corriente, una revista de historia social y literatura de América Latina, v. 8(3), pp. 55-90. 
Lévinas, E. (1997). Totalidad e infinito. Ensayo sobre la exterioridad, Salamanca.

Lévinas, E. (2000). De la evasión. Madrid, Arena Libros.

Lévinas, E. (2002). Algunas reflexiones sobre la filosofía del hitlerismo (1934), FCE. Bs. As.

Meirovich, S. (2011). Preservación dinámica: la protección del patrimonio cultural inmaterial como intervención social (Tesis para optar al grado de Magíster en Trabajo Social). Pontificia Universidad Católica de Chile, Santiago de Chile.

Meirovich, S. (2015). El historiskerstreit chileno: ensayo sobre los rendimientos políticos de la patrimonialización de la memoria. Revista Cuadernos de Estudios Judaicos de la Universidad de Chile. ISSN 0718-8749.

Museo de la Memoria y los Derechos Humanos. Definiciones Estratégicas | Recuperado 20 de julio de 2016, a partir de http://ww3.museodelamemoria.cl/sobre-el-museo/

Richard, N. (2010): Crítica a la memoria (1990-2010), Santiago: Ediciones Universidad Diego Portales.

Rivera Cusicanqui, S. (2010). Ch’ixinakax utxiwa: una reflexión sobre prácticas y discursos descolonizadores. Buenos Aires: Tinta Limón.

Stern, S. (2000): "De la memoria suelta a la memoria emblemática: hacia el recordar y el olvidar como proceso histórico. Chile 1973-1998”, en GARCÉS, M et al. (dir) Memorias para un nuevo siglo. Chile, miradas a la segunda mitad del siglo XX, Santiago: LOM ediciones, pp. 1133.Pinochet, C. (2016). Derivas críticas del Museo en América Latina. Siglo XXI Editores, México.

Vicuña Mackenna, B. (1873ª). Catálogo Razonado de la Esposición de Coloniaje celebrada en Santiago de Chile en Setiembre de por uno de los miembros de su comisión directiva. Santiago: Imprenta del Sud-America. 
Vicuña Mackenna, B. (1873b). La Exposición del Coloniaje. Carta Familiar a Monseñor J.Ignacio Victor Eyzaguirre a propósito de la exposición de objetos de arte, utensilios domésticos y artefactos pertenecientes a la época del coloniaje que tendrá lugar en Santiago en setiembre de 1873. En Revista de Santiago, Santiago, 341-355.

Žižek, S. (2011). En contra de los derechos humanos. Suma de Negocios Vol. 2 N 2, 115-127. 